\title{
Stress Reliever - A Social Responsibility of Mobile Phone Software Engineers and Businessmen
}

\author{
Kashif Nazar Khan ${ }^{1 *}$, Muhammad Shoaib Arshad ${ }^{1}$, Matthew Pinkerton ${ }^{2}$ and Ikpe-etim Nathan Obomufok $^{2}$ \\ ${ }^{1}$ Research Scholar, Comsats University, Islamabad \\ ${ }^{2}$ ZJGSU, Hangzhou
}

Submission: February 26, 2019; Published: March 07, 2019

"Corresponding author: Kashif Nazar Khan, Research Scholar, Comsates Institute of Technology, Chak Shahzad, Islamabad

\begin{abstract}
In this paper, we have proposed to the mobile scientists about a social responsibility to take care about the health of the users by designing a computer-based mobile game so that it could behave intelligently and interactively for stress relieving and health care rather than the traditional leisure. Our study explores the efficacy of intelligent games to keep the interest of a user in computer and mobile usage that helps in the reduction of stress. This review paper highlights the need of social responsibility during the process of App development for mobile phone users.
\end{abstract}

Keywords: Health Care; Stress Reliever; Game Theory; Algorithm; Social Responsibility

\section{Introduction}

Every human being becomes a victim of stress at any stage of his/her life. Millions of people consult doctors to help in curing stress-related issues whereas others try to participate in social gatherings to get them cured. Stress and anxiety lead to traumatic effects and is exposed substantially in low and middle-income countries [1]. Various researches of stress found that different games help people release stress. Computer and mobile games also achieved importance helping in the reduction of stress in users. According to a study in 2007, a stress relief game reduced cortical (stress hormone) levels by 17 percent in people who played the game five minutes a day [2].

By implementing E-Commerce in the business process, industries are exhibiting the corporate social responsibility [3]. Electronic games like Computer, Mobile or Video Games which became popular among teens during 1980s had not only been a source of entertainment but acted as a stress reliever of various factors like over work, depression or anxiety [4]. American Psychological Survey conducted in 2009, concluded that the main causes of stress are a workplace, family relationship matters and social responsibilities especially in the family [5] and different cultures because corporate social responsibility has a varying look with different culture [6]. Health care of the users is also the social responsibility of the firms designing mobile apps for certain cultures. Stress can be released by sharing emotions with someone or diverting the thoughts to some relaxing modes like games.
The games keep track of a user's actions and decide intelligently which best next level should be provoked to the user for keeping his/her interest in the game. In several experiments it has been observed that after playing stress relief game, users become less distracted by rejection, help releasing their stress and anxiety. Today, technology is so advanced that many procedures are controlled through robots and the gesture recognition [7]. Therefore, advancement in the mobile applications for social science advancement is also possible.

The intelligence in the game is being used by researchers as the realistic/intelligent behavior of game characters. Previous studies show that computer and mobile games can provide an active, motivational way for depressed people to access the situation and decide accordingly in a positive way [8]. Game development is becoming more and more challenging because of current exponential growth in software development industries.

Hence, a framework of the intelligent game can be proposed to soothe down the stress conditions of a person based on his/ her psychological and mental conditions. The proposed algorithm intelligently determines the difficulty level (Intelligence Level Determination) on getting two inputs, one through Psychological Stress Calculator, and other through the performance of the user on the game.

The game will be functioned on following dynamics to behave intelligently: 
a. Adjust the difficulty level to be presented next to the user.

b. Record user's capability to play/control the moves.

c. Adjust game's prototype according to the user's mental stress or condition.

The stress relief game can be played on different platforms like single user, multi-users, over the internet and on hand held devices. The game will help the user in relieving stress/depression to some extent.

\section{Related Work}

Game intelligence has been introduced in games using AI techniques. Intelligence can be defined in several ways depending upon the game. The individual sport games like car racing etc., where the environmental factors are considered, the game near to nature has been considered as intelligent i.e. behavior of the car according to the environment, e.g. on a bumpy or slippery road, is it functioning like a car in reality, what is the effect of cold, snow, clean, hot weather etc.; and what happens in case of accidents. How this car being affected by other cars passing near it. How the noise of other objects affects this one. If all these factors are considered while developing the game and the effects are as similar as in real life, then the game is an intelligent game.

Similarly, in strategy games like a case of a fighting video game, if a bullet hits a person on arm or leg, he should not be considered as dead, but behave in a natural way, either he should continue to fight or try to escape from the scene [9]. Effects of a blast near a person should be as like as natural. The behavior of enemies, like their movements, sounds, words should make the game character behaving accordingly in a natural manner.

Social Network Games (SNG) are game applications made available through Social Networking Websites (SNSs), where users play the game with members of their social network, as articulated on the website [10]. These games often take advantage of the social features of SNSs, including access to a list of people interested in the same kind of games. SNGs are a type of networked game. Although computer games were traditionally considered a solitary medium that instigates unsocial behavior, networked games help form a new venture of social phenomenon. Social network games (SNGs) differ from traditional networked games because one could be able to play the game with the people having the same interests.

In the field of social responsibility and corporate transparency, researchers have focused on earnings transparency [11]. which may assist to adhere the unattended wants of the community[12]. A limitation of common mobile games is that players quickly learn the position and behavior of characters [13]. Software developers program these characteristics in such a way that after playing the game for a couple of times, the user learns exactly how the character will act in a specific situation. The game eventually bores, because the player needs only to execute a learned script to defeat the character and overcome all the hurdles he faces.

This pattern has sparked increasing interest in the usage of computational intelligence techniques to control the actions of computer characters, rather than relying on simple heuristics or rule-based systems. Computations, neural networks are being adopted to let software characters learn from their own experience and to predict what a player might do next by taking appropriate actions to meet their own challenges. In this way the game can remain continually novel, posing new tests for the player each time he plays [14]. Online games over the internet should behave like the human on the other side of the computer. The actual user should not judge either he is playing with a computer or a human. A chit chat could be in place with the game [15]

\section{Conclusion}

Games are of different kinds - ranging from single user games to multiple user games. Social Networking Games could be more effective, as a user can interact with a person of his/her own choice or habits and can share the problems/thoughts with each other [16]. For further advancement, at first phase, we have identified the need and described our theme to a simple single user game to redress the stress issues of the mobile users. Our next article will describe the algorithm to design such game.

\section{References}

1. Purgato, M, Ommeren, M. Van, et al. (2018) Addressing stress, depression, and anxiety in people exposed to traumatic events in humanitarian settings: A systematic review and meta-analysis of psychosocial interventions. Journal of Psychosomatic Research 109: 127.

2. Hefner, Dorothée, Klimmt, Christoph, Vorderer, et al. (2007) Identification with the Player Character as Determinant of Video Game Enjoyment. Paper presented at the International Conference on Entertainment Computing. p. 39-48.

3. Farooq, Qamar, Fu, Peihua, Hao, et al. (2019) A Review of Management and Importance of E-Commerce Implementation in Service Delivery of Private Express Enterprises of China. SAGE Open 9(1): 2158244018824194

4. Chen, Yoke Yie, Sivapalan, Subarna, Ganeson, et al. (2010) Design of web intervention to influence youth behavior toward online gaming. Paper presented at the Information Technology.

5. Cohen, Sheldon, Janicki-Deverts, DENISE (2012) Who's Stressed? Distributions of Psychological Stress in the United States in Probability Samples from 1983, 2006, and 2009 1. Journal of applied social psychology 42(6): 1320-1334.

6. Farooq, Q Hao, Y, Liu et al. (2019) Understanding Corporate Social Responsibility with Cross-Cultural Difference: A Deeper Look at Religiosity. Corporate Social Responsibility and Environmental Management.

7. Liu, X, Khan, KN, Farooq et al. (2019) Obstacle Avoidance through Gesture Recognition: Business Advancement Potential in Robot Navigation Socio-Technology. Robotica.

8. DeRosier, Melissa E, Thomas, James M (2018) Video Games and Their Impact on Teens' Mental Health Technology and Adolescent Mental Health. pp. 237-253. 


\section{Annals of Social Sciences \& Management studies}

9. Nareyek, Alexander (2007) Game AI is dead. Long live game AI! IEEE intelligent Systems 22(1)

10. Wohn, Donghee Yvette, Lampe, Cliff, Wash, et al. (2011) The" S in social network games: Initiating, maintaining, and enhancing relationships. Paper presented at the System Sciences (HICSS). $44^{\text {th }}$ Hawaii International Conference on. Hawaii.

11. Zhang, Farooq, Zhang, Liu, Hao et al. (2019) Fair Value and Mispricing: How Domestic Earnings Transparency of Listed Firms Leads to Global Financial Stability. European Journal of International Management.

12. Hao, Y, Farooq, Q Zhang (2018) Unattended social wants and corporate social responsibility of leading firms: Relationship of intrinsic motivation of volunteering in proposed welfare programs and employee attributes. Corporate Social Responsibility \& Environmental Management 25(6): 1029-1038.

This work is licensed under Creative Commons Attribution 4.0 License DOI: 10.19080/ASM.2019.03.555606
13. Fogel, David B (2003) Evolutionary entertainment with intelligent agents. Computer 36(6): 106-108.

14. Egenfeldt-Nielsen, Simon (2005) The basic learning approach behind Serious Games. unpublished paper.

15. Hudlicka, Eva, Payr, Sabine, Ventura, et al. (2009) Social interaction with robots and agents: Where do we stand, where do we go? Paper presented at the Affective Computing and Intelligent Interaction and Workshops. Netherlands.

16. Laird, John, VanLent, Michael (2001) Human-level AI's killer application: Interactive computer games. AI magazine 22(2): 15.

\begin{tabular}{|l|}
\hline \multicolumn{1}{|c|}{ Your next submission with Juniper Publishers } \\
will reach you the below assets \\
- Quality Editorial service \\
- Swift Peer Review \\
- Reprints availability \\
- E-prints Service \\
- Manuscript Podcast for convenient understanding \\
- Global attainment for your research \\
- Manuscript accessibility in different formats \\
( Pdf, E-pub, Full Text, Audio) \\
- Unceasing customer service \\
Track the below URL for one-step submission \\
https://juniperpublishers.com/online-submission.php \\
\hline
\end{tabular}

